\title{
Instructional Strategies That Respond to Global Learners' Needs in Massive Open Online Courses
}

\author{
Trang Phan \\ California State University Fresno
}

\begin{abstract}
The purpose of this study was to describe how MOOC learners' diverse learning needs, stemming from their different language, cultural, and educational backgrounds, were perceived and responded to during the course design and delivery. Participants were 15 instructors and instructional designers in American higher educational institutions who were involved in designing and delivering a wide variety of MOOC subjects on the Coursera hosting platform. This qualitative research study adopted a case study format in which multiple sources of evidence are used (Yin, 1984, p. 3). The participants' insights into specific instructional strategies that were designed especially for MOOC multicultural learners' needs were categorized into three themes: language, content, and engagement. These strategies aimed to provide support and engage learners who have English language barriers, or those who did not have the necessary subject background to keep up with the course, or those who were not familiar with American educational culture. The study also investigated the pedagogical challenges and concerns that the participants faced during and after the delivery of the MOOCs. Typical challenges included confusion triggered by the subject during the discussion, the participants' struggle with the efficiency of peer assessment, and the applicability of the content materials for the global audience.
\end{abstract}

Keywords: Massive Open Online Courses (MOOCs), instructional strategies, diverse learning needs, pedagogical challenges, multicultural learners

Phan, T. (2018). Instructional strategies that respond to global learners' needs in massive open online courses. Online Learning, 22(2), 95-118. doi:10.24059/olj.v22i2.1160

\section{Instructional Strategies That Respond to Global Learners' Needs in Massive Open Online Courses}

Culture is central to learning and essential in communicating, information seeking, and shaping individual and group thinking processes (Ladson-Bilings, 1994). A pedagogy that acknowledges, responds to, and embraces knowledge and insights from different cultural groups provides fuller access to education and makes it more appealing (Gay, 2000; Nieto, 1999). Academic achievement of culturally diverse students will be significantly improved if the knowledge is filtered through their own cultural experience (Au \& Kawakami, 1994; Foster, 1995; Gay, 2000; Hollins, 1996; Kleinfeld, 1975; Ladson-Billings, 1994, 1995). Designing and teaching 
courses for a culturally diverse student population faces the challenges of dealing with students' diverse academic performances and their language problems (Fine \& Handelsman, 2010). On the other hand, the reward is the wealth of inputs by the students into the teaching and learning environment (Fine \& Handelsman, 2010) that allows integration, synthesis, and interdisciplinary learning.

Acknowledging students' culturally diverse backgrounds manifests very differently in an online learning environment than in a traditional classroom. Virtual interaction with the students in an online learning environment precludes the normal nonverbal communication that characterizes the traditional classroom, and these nonverbal cues are different among cultures. While the presence of these cues may or may not produce an effect in a face-to-face classroom, they are missing in an online classroom, which could present a disadvantage to online instructors.

Massive Open Online Courses (MOOCs) are web-based online courses offered for learners around the world at little or no cost regardless of their age, race, social, or educational status. In such a large online learning environment, the learner population multiplies and may be much more culturally diverse than a conventional online course. The need to understand students' multicultural backgrounds that influence learning needs and behaviors is therefore both great and urgent. This study thus aims to explore MOOC instructors' and designers' perceptions of the multicultural learners in these courses, their learning needs and behaviors, how these perceptions were manifested during the design phase, and the different instructional strategies used to respond to the learners' needs and pedagogical challenges the instructors faced when doing so.

\section{Review of Related Literature}

Important issues in online instruction across cultures are (1) impact of learners' culture and language on their learning behaviors (Anderson \& Simpson, 2007) and (2) the design and implementation of specific models of instruction to address students' ways of learning and interacting online (Llambi et al., 2008; Smith \& Ayers, 2006). For example, Johari (2005) suggested responding to learners' language needs, learning styles, and preferences by integrating eight different methods in preparing instructional materials and strategies to match learners to different courses (i.e., language, educational culture, technical infrastructure, primary audience, learning styles, reasoning patterns, cultural context, and social context). Henderson (1996, 2007) built her Multiple Cultural Pedagogical Model of interactive multimedia instructional design that adds to Reeves' 14 dimensions (i.e., pedagogical philosophy, goal orientation, role of instructor, value of errors, motivation, etc.) to incorporate multicultural perspectives and allow learners to maintain their various cultural identities. 


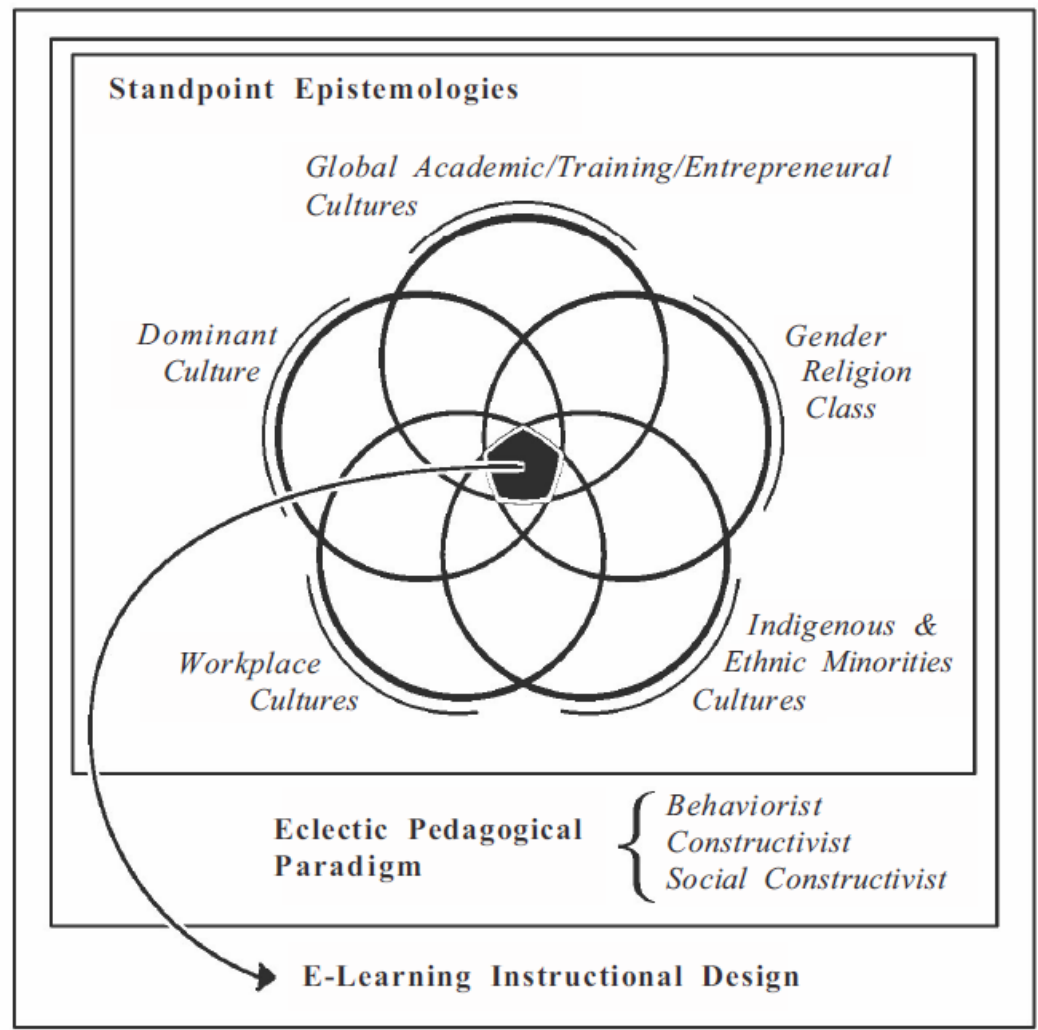

Figure 1. Henderson's Multiple Cultural Pedagogic Model.

Findings on online instruction across cultures indicate that the practices and approaches usually applied in online learning are often at odds with the different ways of thinking and acting by learners of diverse cultures and languages (Ke, Chávez, \& Herrera 2013). These cultural and language differences cause major barriers for the design and implementation of online communication (Dillon, Wang, \& Tearle, 2007). As an example, different usages of words and writing styles can be a major factor that contributes to their feeling of being culturally disconnected. Different learning styles, different forms of communication, and different personal expectations among different cultural groups of learners also impact their learning and communication effectiveness (Dillon et al., 2007).

Quality of instruction is a critical issue when discussing MOOCs. According to Holland and Tirthali (2014), the question of whether learners gain skills and knowledge in a MOOC has not been straightforwardly addressed because institutions might pursue MOOCs for different reasons other than improving teaching and learning (i.e., expanding reach, increasing the reputation of the school or organization, and maintaining brand identity, etc.). Hence, effective online teaching practices, such as individualizing and personalizing interaction with learners, should be encouraged. Research shows learner-instructor and instructor-learner interaction is a critical factor in increasing the persistence of online learners (Croxton, 2014). At present, learnerinstructor interaction in the MOOC learning environment is minimal due to the massive numbers of learners.

Due to some pedagogical similarities between the content-based MOOCs and conventional courses, best practices in MOOCs are also the same ones in a non-massive-scale learning 
environment. Multiple research studies (Bali, 2014; Tomkin \& Charlevoix, 2014; Zhang, 2013) suggest potential best teaching practices in a MOOC environment are within the reach of any instructor. These practices along with brief descriptions are:

- Presentation skills: Video presentations of high quality must have good articulation and must convey a personable message to the learners by means of, but not limited to, a warm, friendly tone, humor and personality, and appropriate body gestures.

- Strong content: Quality, relevant content, and timely topics with accessible resources help to retain the massive audience.

- Managerial skills: These include the management of TAs, course content, and flow (for instance, assigning TAs online hours to maintain 24/7 global presence).

- Personalization: A common strategy is to encourage small group gatherings (by language background, by geographic region, common interests, etc.) to offer different opportunities for peer discussions and feedback. Another strategy is to employ different communication channels, create a synchronous section, point out trending conversations, or make regular personalized email notifications that address learners by name.

- Feedback: This includes the use of additional instant feedback, such as notifications of responses to threads in which a learner posts.

- Fostering learner-centered interaction: Multiple perspectives on interacting with the learners are presented by the participants in Haavind and Sistek-Chandler's (2015) study. For example, one instructor felt rewarded to find conversations that were interesting to him when he surfed the discussion boards. Another instructor felt that building a professional community was the main goal when teaching a MOOC, and yet another enjoyed investing her curiosity in her own subject matter through browsing a large pool of learner discussions (Haavind \& Sistek-Chandler, 2015).

Applying best practices in MOOCs varies greatly by the instructors and the subjects that they teach, and the extent to which the instructor can apply these practices effectively in turn is determined by their own instructional competencies, subject expertise, comfort in using technology in instruction, and the group of learners they are interacting with. Thus, matching the instructor's teaching skills and the learners' diverse needs is a two-way negotiation.

While MOOC design and instructional strategies are somewhat burdened by the massive nature of MOOCs and culturally diverse learning behaviors among the learners, they also benefit from these elements. The open content of MOOCs provides the learners with a participatory, widely connected learning environment that was heretofore impossible (Jacoby, 2014). The connection between the learners, the change of the instructor's role to a facilitator and a fellow contributor, and the recognition and practice of learners' expertise and proactivity in an increasingly networked learning environment such as a MOOC (Stewart, 2013) are the predominant values of this type of course.

\section{Research Questions}

Current issues in MOOC research include the influence of MOOCs on the future of higher education (Billington \& Fronmueller, 2013), the effects of MOOCs on learning and teaching (Martin, 2012), the educational problems MOOCs might solve (Rivard, 2013), the gaps in MOOC research (Liyanagunawardena, Adams, \& Williams, 2013), and the blending of face-to-face classes 
with online MOOC classes (Bruff, Fisher, McEwen, \& Smith, 2013). This paper proposed a new research agenda focusing on (1) insights into learners' behaviors and learning needs determined by their multicultural backgrounds, (2) the use of instructional strategies that responded to the identified needs during MOOC design and development, and (3) possible pedagogical challenges identified by the instructors and course designers when attempting to respond to the needs. The following questions were asked:

- What are the MOOC instructors' and designers' perceptions and understandings of the multicultural learners' needs when designing the MOOC?

- What are the instructional strategies used to address the learners' needs in the MOOC learning environment?

- What are the pedagogical challenges that MOOC instructors and designers might have faced in determining and addressing the MOOC learners' needs?

\section{Methods}

\section{Data Collection}

Qualified participants for this study were professors and instructional designers working at an American institution of higher education and were involved in designing or teaching at least one MOOC on the Coursera platform by the time the interview took place. Their insights and experience in designing and teaching a MOOC on Coursera was foundational to establishing inputs on the MOOC learners and their needs, as well as the development of pedagogical strategies to address such needs.

Merriam (2009), Stake (2006), and Yin (2014) suggest using more than one method for collecting data. For this study, data were collected from two sources:

- investigation of the MOOCs offered by the participants, such as analysis of the course syllabus, including the subject, types of assessment, the calendar, discussion forums, and so on, and

- semistructured interviews with the participants that addressed the following topic domains:

a. information about the MOOC offered by the participant,

b. description of learners' demographic distribution and how this might inform their prediction of students' learning behaviors and needs, and

c. instructional strategies used by the instructors to address the learners' diverse needs and pedagogical challenges in doing so.

The first part of the interview protocol was adapted from the instrument developed by Hollands and Tirthali (2014).

The investigation of the MOOCs on the Coursera platform enabled the researcher to gain knowledge about the MOOC that facilitated conversation during the interview. The interviews were primarily done online using communication tools such as Skype, Google Hangouts, or telephone. Participants in the interview were offered choices on the date, time, and method of communication. Once the candidate agreed to do the interview, a confirmation/reminder email was sent to the participant one or two days prior to the interview date. The interview normally lasted 
45-60 minutes. Follow up emails were used with the permission of the participants should there be need to clarify the transcript. The collected data were run through an artifact review in which they would be compared with one another to determine their validity.

\section{Data Analysis}

All collected data were kept as individual participant cases for review and unification for the study as recommended by Stake (2006) and Yin (2014). The case database included the secondary research results, the interview transcripts, and other related documents found online or provided by the participant. Each interview record was transcribed into a written format and was emailed to the participant for review and approval (Merriam, 2009).

\section{Building Category List}

Each of the approved transcripts was reviewed and sorted by category. A list of categories was created from the contribution of categories from each interview after they were coded. Interviews were coded by broad categories, such as institutional strategies of MOOC development, development of a specific MOOC, MOOC learners' demographic distribution, effects of demographic factors on students' learning behaviors and needs, and instructional strategies used to address the needs.

\section{Building Themes and Testing Findings}

In-depth analysis of the categories emerged during the coding process. These categories were aligned to major themes that were in turn aligned to the research questions. The purpose of the alignment was to determine if the data collected would provide insights and understanding that would answer the research questions. Following the process described by Stake (2006) and supported by Merriam (2009), each case interview suggested a list of individual themes. These themes were run across all the interview cases for findings that may be true for the cases.

\section{Report and Interpret Data}

Collected data were reported both by individual cases and in a consolidated fashion. Individual cases were described without revealing individual participants' identities, yet they provided sufficient details so that conclusions could be drawn by the reader (Merriam, 2009). Data were interpreted in light of themes and assertions found from each participant and were combined to provide the research findings that answered the research questions using Stake's (2006) process. 


\section{Results}

Within the 249 email invitations sent out, three failed to be delivered due to obsolete email addresses, eight generated automatic replies that resulted in no further communication from the recipients, 19 responses resulted in declination for a number of reasons, and 15 were responses of acceptance. The main reasons for declination by the recipients were that they were interested but (1) unable to offer a one-hour time commitment or (2) did not believe they had sufficient expertise on the topic to provide valuable insights. All of the participants held a $\mathrm{PhD}$ degree in the subject area that they teach and had 5-50 years of academic experience. These participants represented a diverse set of institutions and organizations from the public and private sectors as well as their experience with MOOCs and the subjects they taught.

\section{Aspects of MOOC Design That Address Multicultural Learners' Needs}

Most of the investigated MOOCs had the built-in features that demonstrated support for the learning needs of massive and culturally diverse audiences. The built-in support features were grouped into two major categories: language support and course format support. The built-in language support was indicated by the inclusion of transcripts, subtitles, and translation of the content videos into different languages. Course format support included a number of techniques the instructors used to either (1) enhance the learners' comprehension of content (such as the insertion of PowerPoint slides or other forms of visual aids on top of the content videos) or to (2) reinforce learners' engagement, such as (a) creating multiple discussion venues via Coursera discussion forums, Facebook page, or virtual office hours; (b) creating meet-and-greet discussion threads on the discussion forum; (c) encouraging learners to create study groups based on their language background or geographical location; (d) having virtual meetings via Google Hangout; or (e) employing mentors or teaching assistants to monitor the discussion forums, to help translate the course content videos, or to help with assessment. The design efforts in the investigated courses by the participants reflected to a great extent their concerns for diversity in the MOOCs and matched what they shared in the interview. Table 1 shows aspects of MOOC design that address multicultural learners' needs. 
Table 1.

Aspects of Course Design That Address Multicultural Learners' Need

\begin{tabular}{|c|c|c|c|c|c|c|}
\hline \multirow[t]{2}{*}{ Courses } & \multirow[b]{2}{*}{$\begin{array}{l}\text { Language } \\
\text { support } \\
\text { Translation/ } \\
\text { sub-title }\end{array}$} & \multicolumn{5}{|c|}{ Course format } \\
\hline & & $\begin{array}{l}\text { Multiple discussion venues } \\
\text { (Coursera, Facebook page, } \\
\text { virtual office hours) }\end{array}$ & $\begin{array}{l}\text { Meet-and-greet/ } \\
\text { general } \\
\text { discussion }\end{array}$ & $\begin{array}{l}\text { Study groups/ } \\
\text { Google } \\
\text { Hangout }\end{array}$ & $\begin{array}{l}\text { Teaching } \\
\text { assistant }\end{array}$ & $\begin{array}{l}\text { PowerPoint/ } \\
\text { study guides }\end{array}$ \\
\hline Galaxies and Cosmology & $\mathrm{x}$ & $\mathrm{x}$ & $\mathrm{x}$ & $\mathrm{x}$ & $\mathrm{x}$ & $\mathrm{x}$ \\
\hline $\begin{array}{l}\text { Introductory Human } \\
\text { Physiology }\end{array}$ & $\mathrm{x}$ & $\mathrm{x}$ & $\mathrm{x}$ & $\mathrm{x}$ & $\mathrm{x}$ & $\mathrm{x}$ \\
\hline Medical Neuroscience & $\mathrm{x}$ & $\mathrm{x}$ & $\mathrm{x}$ & $\mathrm{x}$ & $\mathrm{x}$ & $\mathrm{x}$ \\
\hline $\begin{array}{l}\text { Questionnaire Design for } \\
\text { Social Surveys }\end{array}$ & $\mathrm{x}$ & $\mathrm{x}$ & $\mathrm{x}$ & $\mathrm{x}$ & $\mathrm{x}$ & - \\
\hline $\begin{array}{l}\text { Object Oriented } \\
\text { Programming in Java }\end{array}$ & $\mathrm{x}$ & $\mathrm{x}$ & $\mathrm{x}$ & $\mathrm{x}$ & $\mathrm{x}$ & $\mathrm{x}$ \\
\hline $\begin{array}{l}\text { Advanced Data } \\
\text { Structures in Java }\end{array}$ & $\mathrm{x}$ & $\mathrm{x}$ & $\mathrm{x}$ & $\mathrm{x}$ & $\mathrm{x}$ & $\mathrm{x}$ \\
\hline $\begin{array}{l}\text { Mastering the Software } \\
\text { Engineering Interview }\end{array}$ & $\mathrm{x}$ & $\mathrm{x}$ & $\mathrm{x}$ & $\mathrm{x}$ & $\mathrm{x}$ & $\mathrm{x}$ \\
\hline $\begin{array}{l}\text { Data Structures Made } \\
\text { Easy }\end{array}$ & $\mathrm{x}$ & $\mathrm{x}$ & $\mathrm{x}$ & $\mathrm{x}$ & $\mathrm{x}$ & $\mathrm{x}$ \\
\hline $\begin{array}{l}\text { Understanding Terrorism } \\
\text { and the Terrorist Threat }\end{array}$ & $\mathrm{x}$ & $\mathrm{x}$ & $\mathrm{x}$ & $\mathrm{x}$ & $\mathrm{x}$ & $\mathrm{x}$ \\
\hline $\begin{array}{l}\text { Curanderismo Part 1: } \\
\text { Traditional Healing of the } \\
\text { Body }\end{array}$ & $\mathrm{x}$ & $\mathrm{x}$ & - & $\mathrm{x}$ & $\mathrm{x}$ & $\mathrm{x}$ \\
\hline $\begin{array}{l}\text { Introduction to Cataract } \\
\text { Surgery }\end{array}$ & $\mathrm{x}$ & - & - & - & - & $\mathrm{x}$ \\
\hline $\begin{array}{l}\text { Powerful Tools for } \\
\text { Teaching and Learning: } \\
\text { Digital Storytelling }\end{array}$ & $\mathrm{x}$ & $\mathrm{x}$ & $\mathrm{x}$ & $\mathrm{x}$ & $\mathrm{x}$ & $\mathrm{x}$ \\
\hline Rural Health Nursing & $\mathrm{x}$ & $\mathrm{x}$ & $\mathrm{x}$ & & $\mathrm{x}$ & $\mathrm{x}$ \\
\hline $\begin{array}{l}\text { Property and Liability: } \\
\text { An Introduction to Law } \\
\text { and Economics }\end{array}$ & $\mathrm{x}$ & $\mathrm{x}$ & $\mathrm{x}$ & $\mathrm{x}$ & $\mathrm{x}$ & $\mathrm{x}$ \\
\hline $\begin{array}{l}\text { Inspiring Leadership } \\
\text { through Emotional } \\
\text { Intelligence }\end{array}$ & $\mathrm{x}$ & $\mathrm{x}$ & $\mathrm{x}$ & $\mathrm{x}$ & $\mathrm{x}$ & $\mathrm{x}$ \\
\hline
\end{tabular}

\section{Goals for Developing the MOOCs}

The goals of offering the MOOCs revealed by the participants were dynamic and somewhat set the tone for how they perceived and responded to MOOC multicultural learners' needs. The overarching and probably most common goals of MOOC pursuit by all the participants was to spread the reputation of the university and to assist people all over the world in learning about the topic, although these participants were also attracted to MOOCs by more than these common goals. 
Most participants were driven by a philanthropic impetus to offer a free gift to the community by creating a MOOC from a campus-based course that they had been teaching. Thus, there existed an issue with time commitment for the MOOC in addition to what they were doing in their institution. One participant noted the following:

I think we are all essentially kind of grapple through this and trying to learn how this all are $[\mathrm{sic}]$ going to work eventually because I think the education is really undergoing profound transformation, and I think most of my colleagues are in a complete denial about that. It'll be very interesting to see how this transformation unfolds. In [name of the university] this is a voluntary activity and, you know, everyone is busy with their lives, and our institution hasn't invested into providing any additional things, this is sort of like a gift to the community.

Another participant expressed a similar struggle she had between the desire to pay more attention to the MOOC versus the constraints of time and other commitments:

The MOOC is like a side thing that I am doing. I was hoping to go through it really carefully and, maybe, change some lectures, add some lectures, definitely change some of the quiz materials, but I honestly haven't gotten through it yet, so I am not even sure what's going to happen.... But that was my hope before the next offer, to be able to really go through it, and put a lot of thought into changing it.

Thus, they believed MOOC deserved more attention and investment from the university:

To go to a higher level of providing educational service, I think institutions will have to compensate people who are actually doing it.... I've done it partly out of curiosity, and partly for just doing different things, and thought that it was a nice thing to do.... But at some point I have actual work to do.... So, the institutions have to come up with a reasonable mechanism, by which all this is organized.

A MOOC could also be designed and implemented as a pilot test for the development of an online joint program between two universities for campus-based students, as in the case of Questionnaire Design for Social Surveys MOOC. MOOCs could also be developed in response to a Coursera request for a specialization by an institution who showed strength on the subject. Finally, the MOOC was a means to offer professional development that targeted K-16 teachers in the state of Texas, as in the Powerful Tools for Teaching and Learning: Digital Storytelling MOOC.

\section{MOOC Learners: Expectations and Reality}

Most of the participants reported that they came to MOOC design and development with some expectations of diversity among the audience. Yet they became surprised at the tremendous volume of diversity among the population in regard to their age; their language, cultural, ethnic, and educational background; and their patterns of engagement in the course. Table 2 describes the MOOC's expected audience and then the actual participants. 
Table 2.

Expectations and Reality of MOOC Learners' Background

\begin{tabular}{|c|c|c|c|}
\hline Participant & MOOC & Learners' Expected Backgrounds & Reality \\
\hline 1 & $\begin{array}{l}\text { Galaxies and } \\
\text { Cosmology }\end{array}$ & $\begin{array}{l}\text { - Physics } \\
\text { - Astronomy } \\
\text { - Cosmology } \\
\text { - Anyone interested }\end{array}$ & $\begin{array}{l}\text { - } 20 \% \text { expected audience } \\
\text { - } 20 \% \text { science education } \\
\text { - } 60 \% \text { regular people } \\
\text { - Age: } 16-82 \\
\text { - Global audience }\end{array}$ \\
\hline $2 \& 3$ & $\begin{array}{l}\text { Introductory } \\
\text { Human } \\
\text { Physiology }\end{array}$ & $\begin{array}{l}\text { - Biology } \\
\text { - Anyone interested }\end{array}$ & $\begin{array}{ll}\text { Wide range of } & \bullet \text { Humanities: } 15.1 \% \\
\text { academic } & \text { - Natural science: } 17.8 \% \\
\text { backgrounds } & \text { - Social science: } 13.9 \% \\
\text { (Engle, } & \bullet \text { Health science: } 30.6 \% \\
\text { Mankoff, \& } & \bullet \text { Professional: } 11.6 \% \\
\text { Carbrey, 2015) } & \text { - Technical: } 11.1 \%\end{array}$ \\
\hline 4 & $\begin{array}{l}\text { Medical } \\
\text { Neuroscience }\end{array}$ & $\begin{array}{l}\text { - Doctors - physicians } \\
\text { - Those with neuroscience knowledge } \\
\text { - Anyone interested }\end{array}$ & $\begin{array}{l}\text { A lot of non-native speakers of English (who } \\
\text { did or did not struggle with the language) }\end{array}$ \\
\hline 5 & $\begin{array}{l}\text { Questionnaire } \\
\text { Design for Social } \\
\text { Surveys }\end{array}$ & $\begin{array}{l}\text { Students and professionals from all } \\
\text { fields of social science }\end{array}$ & N/A \\
\hline 6 & $\begin{array}{l}\text { Specialization in } \\
\text { Intermediate Java } \\
\text { Software } \\
\text { Engineering* }\end{array}$ & $\begin{array}{l}\text { - Undergraduates around the world } \\
\text { - Working professionals } \\
\text { - Programming }\end{array}$ & Diverse programming skill levels \\
\hline 7 & $\begin{array}{l}\text { Understanding } \\
\text { Terrorism and the } \\
\text { Terrorist Threat }\end{array}$ & $\begin{array}{l}\text { U.S. government officials (Homeland } \\
\text { Security, Intelligence, Justice, etc.) }\end{array}$ & $\begin{array}{l}\text { - } 30 \% \text { from developing economies } \\
\text { - } 30 \% \text { from the U.S. } \\
\text { - Subject expert (to seek network) vs. novice (to } \\
\text { learn something new) }\end{array}$ \\
\hline 9 & $\begin{array}{l}\text { The Holocaust: } \\
\text { The Destruction of } \\
\text { European Jewry }\end{array}$ & Anyone interested & People who lived during the Holocaust \\
\hline 10 & $\begin{array}{l}\text { Curanderismo Part } \\
\text { 1: Traditional } \\
\text { Healing of the } \\
\text { Body }\end{array}$ & Anyone interested & $\begin{array}{l}\text { - Mexicans } \\
\text { - Tex-Mex }\end{array}$ \\
\hline 11 & $\begin{array}{l}\text { Introduction to } \\
\text { Cataract Surgery }\end{array}$ & $\begin{array}{l}\text { - Residents in the ophthalmology } \\
\text { residency program } \\
\text { - Anyone interested }\end{array}$ & $\begin{array}{l}-<50 \% \text { expected audience } \\
->50 \% \text { laypeople }\end{array}$ \\
\hline 12 & $\begin{array}{l}\text { Powerful Tools } \\
\text { for Teaching and } \\
\text { Learning: Digital } \\
\text { Storytelling }\end{array}$ & $\begin{array}{l}\text { - Primarily Texas K-12 teachers } \\
\text { - Anyone interested }\end{array}$ & $\begin{array}{l}\text { - } 1 \% \text { Texas K-12 teachers } \\
\text { - Everyone else }\end{array}$ \\
\hline 13 & $\begin{array}{l}\text { Rural Health } \\
\text { Nursing }\end{array}$ & $\begin{array}{l}\text { - Nurses } \\
\text { - Other backgrounds }\end{array}$ & Global audience \\
\hline 14 & $\begin{array}{l}\text { Property and } \\
\text { Liability: An } \\
\text { Introduction to } \\
\text { Law and } \\
\text { Economics }\end{array}$ & Anyone interested & $\begin{array}{l}\text { - } 70 \% \text { Americans } \\
\text { - } 30 \% \text { internationals }\end{array}$ \\
\hline 15 & $\begin{array}{l}\text { Inspiring } \\
\text { Leadership } \\
\text { through Emotional } \\
\text { Intelligence }\end{array}$ & Anyone interested & Global audience \\
\hline
\end{tabular}

*This specialization included five courses: 1. Object Oriented Programming in Java, 2. Advanced Data Structures in Java, 3. Mastering the Software Engineering Interview, 4. Data Structures Made Easy, and 5. Capstone: Analyzing (Social) Network Data. 


\section{Participants' Perceptions of Diversity}

Participants' perceptions of diversity can be categorized into two groups: (1) those who perceived cultural differences among learners' attitudes toward and satisfaction with MOOCs and (2) those who saw the merits of MOOCs with diverse audiences. In regard to learners' perceptions of MOOCs, one of the participants reviewed the striking cultural differences they observed among the audience's attitude toward, appreciation of, and satisfaction with the course:

One interesting thing that caught my attention is a lot of students, and I think most of them are probably Americans ... were having expectations that were not warranted by the fact.... They're sort of feeling extremely entitled ... demanding better service, and I had to remind people that they are not paying customers .... On the other hand, there are a substantial number of students ... and those are I think from places like India, or China, or South East Asia in general, or Africa ... were extremely grateful... They were thrilled to have the opportunity to actually participate in a ... class from where they are.

To illustrate the counterargument, the participant provided an anecdote of how a student from Egypt expressed their appreciation of the MOOC:

At one point, I got an email from a fellow in Egypt, who said "I am emailing you on behalf of my brother who is taking your class, who could not email you himself. And here is the fax: "Professor, I love your class, I am so sorry I will not be able to finish it because I was arrested by military police in Egypt during the demonstration, and I don't know when I will get out, but I am so sorry." I am thinking, "Good God, if I were arrested by military police in Egypt, ... class will be the last thing in my mind." This person was so grateful that they had the opportunity that they took trouble to send this message from jail.

In the same category, another participant believed that MOOCs were more appreciated by the learners from parts of the world that had limited access to quality learning resources:

The real value of the MOOC is not that some college sophomores are going to see it in America where the alternative is that the college sophomores could get it in a college class. It's going to be somebody in Vietnam or somebody in Peru or somebody in Africa for whom the alternative is not an American college course but nothing at all. And so for that student, this is an incredible opportunity. Yet many of them wrote to me to tell me it was the best part of the whole experience. They said if it wasn't for this I wouldn't have any idea of the subject that you're talking about and there's no opportunity in my life to do anything remotely like this and yet, it just cheerfully changed my attitude about it completely.

Most participants shared the belief that major merits of MOOCs were created by the diverse student body. They stated that widely diverse MOOC audiences enriched the learning outcomes with their diverse and authentic viewpoints, experiences, and personal stories. Furthermore, another advantage of having a massive audience in the course was that the learners could support and encourage each other during the learning process. Here is an example:

Another aspect of MOOCs, what I would call spontaneous self-crowdsourcing of education .... Students will post questions on the forums, and other students would answer them. In many cases, almost all cases, those would be excellent answers ... 
sometimes it's a fairly trivial thing over such and such lecture, and sometimes it will be a person who actually has a real expertise in that particular aspect, and answered it better than I would.

Yet more evidence of the merits of MOOCs was attributed to the expertise and reputation of the instructor and the institution and the instructor's availability to have a live conversation with learners across the globe:

I try to do a live chat, about once a month. When I do the live chat people call in for an hour and a half on a video chat and they can ask any questions. The last calls were somebody from Tehran with questions, somebody calling from British Columbia, Canadian teacher who is on strike so she's at home. A young man from Amman Jordan, a high school student from the UK, a man and a woman both are working in Lagos Nigeria called and people from a few U.S. cities. Oh and a young man from India. It was 4 o'clock in the afternoon my time in Cleveland at the university and I said "What time is this there for you?" and he said "its 2:30 in the morning," I said "why aren't you in bed?" he said "Oh, professor, I've been waiting for so many weeks to be able to talk to you."

Perceptions of Multicultural Learners' Needs in a MOOC and Instructional Strategies Used to Address the Needs. Instructors' and instructional designers' perceptions of multicultural learners' needs were paired with the instructional strategies they used to address such needs. The three themes that emerged were language, content, and engagement.

Theme 1: Language. Most of the participants were mindful of the existence of non-native speakers of English among the learners and concerned that these learners might face more language problems when drawn to more specialized subjects. To help solve this problem, the instructor had the teaching assistants (TAs), who were former MOOC students with the relevant background, translate the entire course into different languages, such as Chinese or Portuguese. The instructors revealed that it was hard to assess the course when it was in a foreign language, but it has been successful, as evidenced by its four runs, and there were learners who kept coming back either because they did not pass the first time or to help other people. The instructors shared a confession made in the Google Hangout section by a student who attended the course four times:

"My English language was not very good. I am trying to learn because I want to get into the medical school" said the student. In the second run he spoke more fluently. His English was really improved and by the fourth run he got on and he said "oh I got into the medical school I am so excited that this course has helped me so much" and he was really selling our course. He said that the course helped him both to learn English as well as to master the information he needed to get into medical school. We thought that was really animated and nice.

Providing PowerPoint slides to aid the video lectures was another common language-support strategy. Others spoke slowly and clearly in the video lectures for their non-native speakers of English:

I've had the experience myself of being a non-speaker in a foreign country and been struggling to learn German for my whole life so when I was in Germany I appreciated that people speak German to me slowly and clearly. At my university I have many foreign students. Many of them are not native English speakers and so 
for years I've been conscientious that what they need is for me to speak clearly and slowly. So one of the nicest things about my course was people in places like Burma would send me an email on the chat board to say "thank you for speaking slowly and clearly" and that made me feel great.

Or some instructors allowed the learners to upload their works in a language of their choice:

One of the things that we have done is we have given the option for learners to upload their videos in whatever language they prefer rather than English except if there aren't enough learners who speak that language, they might not be able to be graded. And so the grading depends on having 3 peers who will be able to watch and respond to the video. They might have to work a little harder to find peers who will grade that work because other students won't understand it.

Theme 2: Content. The participants in this study went above and beyond in giving attention to different groups of learners and are deeply concerned about content comprehension of learners who did not have the required subject background knowledge or who were non-native speakers of English. The content support strategies included (1) supplementing the video lectures provided to the learners with additional resources in different formats; (2) providing study guides for the content in the video lectures; (3) gathering global insights, ideas, and stories from the learners; (4) providing notes (that consisted of the same information as in the content video but written in paragraphs like a textbook) for video lectures; (5) customizing content videos for different knowledge levels for learners of different academic backgrounds and skill levels; and (6) simplifying the content presentation and utilizing international content and examples to make the content relevant for an international audience.

All participants provided supplemental resources for their MOOC learners. These supplemental resources provided scaffolding subject knowledge that appeared especially helpful for the novice learners and allowed further exploration or study in-depth for others.

In the Introduction to Human Physiology MOOC, the strategies used by the instructors to facilitate content comprehension for the international learners included the use of notes that went along with video lectures. These notes were written in paragraphs and carried the same information as the videos. They also gave learners - especially those who were struggling to read Englishmore time at the end of the course to study for the exam.

In the Medical Neuroscience course, the instructor provided study guides to help learners, especially those who had less neuroscience background, better understand the video lectures. In the series of programming courses offered by the University of California at San Diego (UCSD) that were intended for undergraduates around the world and working professionals with programming backgrounds, the content materials were designed for the intermediate level, and yet the audience was more diverse in terms of their programming background and skill levels. To accommodate that, the instructors provided customized video lectures that targeted different groups of learners with different programming skills. They incorporated test quizzes for learners with adequate programming backgrounds and support videos with additional scaffolding knowledge for people with less background in programming. The videos were structured to allow people to review the core concepts being taught and came with programming assignments to be submitted at the end of each module. These videos addressed common conceptions and mistakes and provided a few hints about the programming assignments. 
The other sequence of videos, the concept-challenged videos, were made for learners with different backgrounds, adopted from the peer instruction model of teaching computer science. The learners watched the videos, replied to the question, and were showed a segment of three university students with qualified backgrounds discussing common misconceptions surrounding the question in simple language before the instructors revealed the correct answer. The instructors would present a concluding video to explain what the correct answer was and why.

In a number of MOOCs, a majority of learners who signed up for the course came from outside of the United States. The instructors of these MOOCs therefore fostered content comprehension for non-native speakers of English by internationalizing concepts and utilizing examples that were more internationally representative. For example, to customize the content presentation to meet $75 \%$ of the learners' needs who came from outside of the United States, the instructor of the Powerful Tools for Teaching and Learning: Digital Storytelling MOOC utilized examples that were internationally representative:

If we show a picture of something, rather than showing a picture of the Empire State building which is a famous building in the U.S. we show a picture of the Taj Mahal for example, or the Eiffel Tower thinking that might be more recognizable. We try to do things that are more global and not just focus on the U.S. And we try to break down all the steps of the digital storytelling process so that they started it at the very beginning and we understood that people who signed up for MOOCs English is their second or third language and so we did not assume that they knew as much about everything.

The instructor who taught a subject that reflected deep Western-rooted ways of thinking, the Property and Liability: An Introduction to Law and Economics MOOC, was even more deeply aware of simplifying the concepts and ideas for the global audience. The instructor made an effort to pierce through the concepts and the topic, as he was mindful that they were both challenging and unfamiliar to the international learners:

It's about private property, it's about respecting individuals, and it's about having a distance between you and the state. This is not stuff for example that university students are going to learn in Beijing. This is the subversive stuff in Asia, subversive stuff in China, subversive stuff in Vietnam, subversive stuff in a lot of places in the world. So various students in Beijing are listening to these lectures, they are doing something about Western liberal thinking that they are not likely to hear anywhere else in China because the governments don't recognize these sorts of rights. So I think of my multicultural students as the way I think of all the other students except to say that I try very hard to not talk about anything in the course that requires you to be in America to understand this.

Instructors also enriched and diversified the content strategically by recruiting insights, ideas, and stories from their global MOOC learners. This, however, depended on the subject, particularly the capacity and degree to which the ideas, concepts, or process could be universally interpreted and applied. For example, a diversity-embracing strategy used in the Powerful Tools for Teaching and Learning: Digital Storytelling MOOC was to share exemplary submissions of digital stories by their former MOOC learners (with permission obtained) with the next generation. The rationale was that even though each story had a cultural context on its own and carried its own 
primary nuances, it could be felt and understood by people of different cultures, especially when it was creatively told with passion from the narrator:

We give them example stories of different topics but basically we want people to be creative. We want them to pick something that is personally meaningful to them. I think that's what we've learned from teaching digital storytelling is that the best stories come from people who pick a topic that they find personally meaningful so they are motivated to put together a story that comes to the viewers who want the story and they will respond better because they can feel the passion that the story teller had.

Or, the instructors were specifically looking into the global insights from the students' postings because of the nature of the subject, as in the Rural Health Nursing MOOC:

We addressed unconscious bias, which stimulated a lot of discussion. We did an assessment of resources (i.e.) geographic, economic, political and social aspects of healthcare that the students were provided to see how they're related to health. We even read the posts from participants around the world and got into an exchange with someone who was in India. He was struggling with some of the cultural diversity that involved the castes there. If you're in one particular caste level, you're provided with healthcare that's somehow different from the other caste level from the other areas of the country.

Dealing with the massive diverse audience in a MOOC on a daily basis both challenged the instructors and allowed them to experience the immediate effects of their involvement and pedagogical innovation in the course. The learners' feedback, which was faster paced, nontraditional, spontaneous, and more diverse than that in a conventional course, contributed significantly to this experience.

Theme 3: Engagement. A study by Phan, McNeil, and Robin (2016) indicated that learners who demonstrated active engagement in a MOOC tended to outperform the ones who did not prioritize a similar trait. Thus, participants in this study noticed different patterns of engagement by the learners due to their ethnicity, language, and educational background. These global learners brought with them aspects of their native language and cultural identities that were shaped by their educational background when immersing themselves in the mainstream American classroom culture, even in an online environment.

The implementation of engagement-facilitation strategies was dependent on the subjects being taught, the instructors' and course designers' experiences with and exposure to a global audience, and their time commitment. Learners in the MOOCs investigated in this study were granted the opportunities to extensively communicate with one another from different parts of the world, across different skill levels, and regardless of their language and educational background due to the application of a wide variety of engagement-facilitation strategies by the participants.

A common practice of engagement used by the participants was building a virtual community by personalizing the discussion forum on Coursera with "meet-and-greet" sessions where the learners could introduce themselves, or by organizing the discussion threads by the lecture topics that allowed learners to keep track of different questions. Another strategy used by UCSD to draw in the learners in the specialization MOOCs was the use of real-world resources, such as "When I struggle," where the instructors or the students talked about their experience going 
through the same materials and what was hard for them and what strategy they used to overcome the challenges, or real-world videos of Google engineers talking about the concepts taught in the course and their real-world applications.

The value the discussion forums, according to the instructor of the Property and Liability: An Introduction to Law and Economics MOOC, was created by the learners' contribution, with the instructor being a monitor or a fellow participant:

Besides posting the weekly announcement, I would spend maybe 45 minutes to an hour, four or five times during the week in the chat room and most of the time I wouldn't say anything. I just read what people were doing. Occasionally somebody would address something specifically to me that I thought needed to be addressed then I responded to that for everybody.

A couple of strategies used by participants at UCSD were (1) requiring the learners to take charge of their learning by uploading videos of themselves explaining concepts as part of the course assignment and (2) extending the discussion forums to make it an input-gathering place where learners shared their inspiring stories:

The other thing we have done is we have an extended discussion forum. Our learners are really active on the discussion forum and really supportive of one another. They share the stories about being stay-at-home parent for 10 years trying to get back into the workforce or moving from one aspect of industry to another and they share tips with one another about how to write their resume or how to prepare for interviews. It's just amazing to see this community form from around the world, people who are in the States, in Europe, in Russia and it's just amazing and they are working together, giving each other advice.

Yet a number of instructors offered multiple channels for instructor-learner and learner-learner interaction:

I've tried different varieties of interacting with students...they certainly appreciate me answering questions in forums. I tried Facebook, Google Hangout, virtual world, and nothing has quite really caught on yet but I think that will be another major issue for the educational industry to sort out how to provide the human interaction experience where knowledge really gets to.

There were certain topics that could trigger some tricky interactions among the learners and which prompted the instructor to strategize their instruction to solve the problem or to distract the audience away from it. For example, in the Understanding Terrorism and the Terrorist Threat MOOC, there was a growing divide between the learners with advanced knowledge on the topic and the other group that had no background knowledge who wanted to learn something new. Recognizing this disillusionment on the discussion board, the instructors broke the audience off into 13 different regional discussion groups and structured the discussion so that people from the same region discussed among themselves and then moved toward other groups. This was perceived as a vehicle to ease out cross-cultural issues. To set up this exercise on the discussion board, the instructors did a survey on the audience's personal experience across the regions. The learners who were required to share their personal stories and opinions about the topic felt they contributed to the discussion: 
We actually had people who affiliated or consider themselves affiliated to radical groups in the same conversations with Nigerian police officers and American agents and Poland refugee workers, etc. So it was really interesting, really active and productive.

Finally, a strategy that the instructor in the Inspiring Leadership through Emotional Intelligence MOOC tackled to encourage engagement, especially in students from the Middle East and women from Japan, Korea, and China, who were normally less vocal than their Western counterparts, was to bring up their voices and insights in the discussion. The instructor believed this was an effective way to make them speak in the class and that it was culturally helpful for students who came from the cultures where they were supposed to be silent.

Pedagogical challenges in addressing multicultural learners' needs in a MOOC. The participants reported facing a number of pedagogical challenges in their attempts to respond to the culturally diverse MOOC learners. These challenges were strongly connected, but not limited to dealing with different aspects of multicultural learners' needs. These challenges could stem from a particular subject, the instructor's personal experience and exposure to a global audience and the context of MOOCs, the instructor's preference for and exposure to online interaction, and finally their time commitment to MOOCs.

Some MOOCs investigated in this study had topics that generated controversies and created heated conversations among the learners. That was the case of the Understanding Terrorism and the Terrorist Threat MOOC or the Rural Health Nursing MOOC, where the invitation of global, rural nurse learners to the discussion allowed the gathering of great insights and revealed learners' struggles for which there were not necessarily solutions. For example, what nurses could do legally varied wildly depending on their respective countries, states, or regions.

In a different category, some instructors described their struggle with the efficiency (i.e., whether it was done on time) with the peer assessment process and the subjectivity and quality of the feedback (i.e., whether it met all the goals or not). One instructor asked how instructors can get learners to think about the personally meaningful digital stories they produce in educational contexts to support and improve the teaching and learning process, as in the case of the Powerful Tools for Teaching and Learning: Digital Storytelling MOOC.

Other instructors confessed that it was very challenging to target the level of difficulty of the materials to broadly serve such diverse groups of learners in their MOOCs, and they became frustrated that what was offered sometimes was not what some learners wanted. They also felt some disconnection from the MOOC learners as opposed to the connection they felt with those in a campus-based course, as they could not see them and attach names or faces to individual learners. Or they felt frustration that they did not get responses about their learning outcomes:

I feel that gratification as an instructor I would like to know "did they learn?" "Did the course help them?" "What are they going to do with it?" "How are they incorporating this into their education?" and I don't get that response necessarily.

Finally, a number of instructors who were interviewed expressed their struggle with the limited time commitment they could make for MOOCs while desiring to modify and improve the MOOCs. For most of the instructors who were performing a full load of responsibilities at their institutions, MOOCs were a side task that was done either out of intellectual curiosity or with a philanthropic drive to serve the community, among other impetuses. They believed that the 
institutions should come up with a reasonable and organized mechanism to make MOOCs an independent item on the faculty's agenda, especially when learners were required to pay for the course, so that the expectations for the quality of MOOC design and delivery from the learners would be higher.

\section{Conclusions}

Aspects of MOOC design that responded to diverse learners' needs included the built-in course components that offered choices of language of assignment submissions and content materials categorized by levels of difficulties for learners of different ethnic and language backgrounds, educational levels, and so on. During the delivery phase, indications of instructional strategies that addressed multicultural learners' needs were language support, content support, and multiple forms of online interactions (i.e., instructor-student, student-student) to encourage student engagement. Most of the instructors concurred that language played a role in MOOC learning outcomes, especially for learners who spoke English as a second or foreign language. In regard to the course content, the participants showed various concerns regarding content comprehension, especially for two groups of learners: those who did not have the required background knowledge for the course and non-native speakers of English. The content support strategies usually targeted these two groups of learners. Content accommodations to better support global learners were adding supplemental learning resources in different formats; creating study guides for video lectures; utilizing global insights, ideas, and stories; creating notes for video lectures; and customizing the content videos for learners of different academic backgrounds and skill levels. Cultural adaptation in the course content design was reflected as the simplification of the content presentation and the utilization of internationalized content/examples. Support for the international learners with content comprehension included insertion of PowerPoint slides or other forms of visual aids on top of the content videos; encouragement of study groups based on language background or geographical location; or employment of mentors or teaching assistants to monitor the discussion forums, to help translate the course content videos, or to help with assessment. The instructors and designers also showed concerns about patterns of engagement by learners of different ethnicities and educational backgrounds. Engagement-facilitation strategies were usually targeted at minority groups of learners who were not accustomed to the culture of American higher education. The design efforts by the instructors and instructional designers in the investigated courses reflected to a great extent their concerns for diversity in the MOOCs and matched what they shared in the interview.

A common challenge faced by most of the instructors and course designers, which aligned with the findings of Ferguson and Sharples (2014), was that they were not able to provide prompt feedback to the learners but had to heavily rely on the TAs to monitor the discussion forums and to respond to questions from the learners. There were also problems with a high volume of issues in the course that had to be managed by a handful of TAs. Another common challenge was the struggle with the time commitment for the MOOCs, as most of these instructors had to teach regular courses on campus besides conducting research and performing other vital responsibilities in their institutions. They expressed the dilemma they had between the desire to improve the MOOCs and reach broader audiences versus the limited time they had for MOOCs.

Another type of challenge peculiar to niche subjects was that the courses were designed for learners with certain background knowledge of the subject, but in reality the audience was more 
diverse and included people who did not have the background of the target audience. As a consequence of dealing with a broader, more diverse group of learners that they were not fully prepared for, the instructors received different kinds of feedback from the learners about the level of difficulty of the course, the attitude toward what was available, and the demand for better service, including complaints when the service was not up to students' satisfaction. Another challenge for the participants who taught the MOOCs of niche subjects that required prerequisite knowledge was that they sometimes felt they did not have sufficient expertise to teach the subject to a global audience, as they were trained to work with specific audiences within the United States. There was also an issue with students in other countries not having the correct equipment to perform the tasks. Finally, some instructors who were accustomed to knowing their students well in a traditional classroom struggled with connecting with the learners in the online learning environment, especially at the massive scale of MOOCs. The instructors had the same strong desire to know whether and how much the students learned, as well as how they applied what they learned to practice in the virtual classroom. In the meantime, they understood that this was hardly possible in a MOOC learning environment as opposed to a conventional classroom due to the come-andgo of the MOOC learners and the lack of obligation for them to commit.

\section{Strengths and Limitations}

As MOOCs become a more widespread phenomenon in higher education, and formal credits and recognition evolve, responses to questions about the instructional quality of the MOOCs have become more urgent and critical. The researcher believes that one of the most critical issues of developing MOOCs revolves around the umbrella question of how to deal with the global audience's diverse learning needs. This study contributes to the mission of educating the global audience by providing these insights: (1) instructors' and course designers' perceptions about multicultural learners' needs and how these perceptions and identification of the learners' needs guided them in designing and delivering the course, (2) instructional strategies they applied to respond to such needs, and (3) pedagogical challenges they had while pursuing these goals.

The major contribution of this study is the addition of the voices of the instructors who designed, developed, and taught the MOOCs to the literature of MOOC research. Various insights into global learners' backgrounds by the MOOC instructors and designers that shaped their responses to learners' learning behaviors and needs contributed to the knowledge base of MOOC instruction. Instructional strategies that these instructors used to deal with multicultural learners as well as to engage them and accelerate their performances in the MOOCs across disciplines can be valuable sources of reference for subsequent generations of MOOC instructors and designers. In the meantime, the pedagogical challenges reported in this study can serve as references for instructors and course designers when starting their MOOC design and delivery journey.

A limitation of this study is the lack of generalizability of the findings. Even though the participants represented diverse disciplines and both public and private higher education institutions in the United States, it does not reveal the complete story of multicultural learners' needs in MOOCs, how they are perceived and responded to by instructors, or what pedagogical challenges became evident along the way. In addition, only online modes of communication were used for data collection in this study. Other methods, such as in-person observation and discussion, could reveal additional findings. 


\section{Implications for Practice}

The greatest implication for practice from this study is that MOOCs will probably never be one-size-fits-all courses due to their unconformable body of learners. All of the narratives, anecdotes, and lessons learned from MOOCs serve as a source of reference at best. A successful MOOC model cannot be simply transplanted or replicated because aspects of the learners' diversity (what the researcher would refer as microlevel diversity, in which evidence of diversity is shown within an inner group of learners who are normally bounded within a territory and share the same language, culture, and educational background, and macrolevel diversity among learners who share none of the above) are magnified and become more critical variables in a MOOC learning environment. The instructors and course designers have to pick and choose their instructional content by trying out different instructional strategies and may have to accept the possibility of failure in the design and delivery of MOOCs. Each MOOC is a unique package: the way it is designed, the philosophy behind it, and most importantly the audience who participates. This is the nature and the beauty of this type of online learning environment: While it gives the instructors and course designers exciting experiences and the freedom of design, it also requires them to provide flexibility, choices, and options for the learners. This could mean a tremendous time commitment on designing a MOOC and challenges in considering all aspects of the learners' diversity.

Findings in this study should not serve as a single reference for MOOC design and development. Instructors and course designers of MOOCs should also consider guidelines on the Coursera Partner Help Center and other sources of references and publications from institutions who pioneered MOOC design and delivery.

\section{Recommendations for Future Research}

There are many possibilities to extend the findings of this study in order to tell a more complete story of how MOOC instructors and course designers perceive and respond to multicultural learners' needs. It is recommended that replication of this study be conducted on another MOOC platform besides Coursera, such as edX, Future Learn, Stanford Online, or Udacity, to name a few. Extending this study to another MOOC platform may help identify pedagogical strengths and weakness in different MOOC providers and their potential impact on learning outcomes.

In regard to methodology, it is recommended that the data collection be extended with the inclusion of face-to-face interview components and classroom observations with instructors and instructional designers who develop and launch MOOCs in addition to the online and telephone interview methods employed in this study. Classroom observations on campus would provide great quality of data sources for the study. These resources would in turn set the background and provide guidance for further exploration on pedagogical challenges and instructional strategies at other institutions.

Another possibility to extend this study is to investigate the pedagogical transformation between MOOCs and conventional campus-based courses offered by the same instructors. Insights into pedagogical transformation between MOOCs and conventional courses made by the instructors who teach MOOCs and campus-based courses could paint a larger picture of pedagogical approaches used in both environments. 


\section{Acknowledgement}

The author would like to thank the 15 instructors and designers from 13 American higher education institutions who designed and taught MOOCs and who participated in the study. Without them the research study could not have been made. 


\section{References}

Anderson, B., \& Simpson, M. (2007). Ethical issues in online education. Open Learning, 22(2), 129-138. doi:10.1080/02680510701306673

Au, K. H., \& Kawakami, A. J. (1994). Cultural congruence in instruction. In E. R. Hollins, J. E. King, \& W. C. Hayman (Eds.), Teaching diverse populations: Formulating a knowledge base (pp. 5-23). Albany: State University of New York Press.

Bali, M. (2014). MOOC pedagogy: Gleaning good practice from existing MOOCs. MERLOT Journal of Online Learning and Teaching, 10(1), 44-56. Retrieved from http://jolt.merlot.org/vol10no1/bali_0314.pdf

Billington, P., \& Fronmueller, M. (2013). MOOCs and the future of higher education. Journal of Higher Education Theory and Practice, 13(3/4), 36-43.

Bligh, J. (2002). The first year of doctoring: Still a survival exercise. Medical Education, 36, 23. doi:10.1046/j.1365-2923.2002.01129.x

Bruff, D., Fisher, D., McEwen, K., \& Smith, B. (2013). Wrapping a MOOC: Student perceptions of an experiment in blended learning. MERLOT Journal of Online Learning and Teaching, 9(2), 187-199. Retrieved from http://jolt.merlot.org/vol9no2/bruff_0613.htm

Croxton, R. A. (2014). The role of interactivity in student satisfaction and persistence in online learning. MERLOT Journal of Online Learning and Teaching, 10(2), 314-325. Retrieved from http://jolt.merlot.org/vol10no2/croxton_0614.pdf

Dillon, P., Wang, R., \& Tearle, P. (2007). Cultural disconnection in virtual education. Pedagogy, Culture \& Society, 15(2), 153-174. doi:10.1080/14681360701403565

Engle, D., Mankoff, C., \& Carbrey, J. (2015). Coursera's introductory human physiology course: Factors that characterize successful completion of a MOOC. The International Review of Research in Open and Distributed Learning, 16(2), 46-67. Retrieved from http://www.irrodl.org/index.php/irrodl/article/view/2010/3317

Ferguson, R., \& Sharples, M. (2014). Innovative pedagogy at massive scale: Teaching and learning in MOOCs. In C. Rensing, S. de Freitas, T. Ley, \& P. Muñoz-Merino (Eds.), Open learning and teaching in educational communities (pp. 98-111). Graz, Austria: Springer International Publishing. doi: 10.1007/978-3-319-11200-8_ 8

Fine, E., \& Handelsman, J. (2010). Benefits and challenges of diversity of academic settings. University of Wisconsin-Madison: Women in Science and Engineering Leadership Institute. Retrieved from http://wiseli.engr.wisc.edu/docs/Benefits_Challenges.pdf

Foster, M. (1995). African American teachers and culturally relevant pedagogy. In J. A. Banks \& C. A. M. Banks (Eds.), Handbook of research on multicultural education (pp. 570-581). New York: Macmillan.

Gay, G. (2000). Culturally responsive teaching: Theory, research, and practice. New York: Teachers College Press.

Haavind, S., \& Sistek-Chandler, C. (2015). The emergent role of the MOOC instructor: A qualitative study of trends toward improving future practice. International Journal on ELearning, 14(3), 331-350. 
Henderson, L. (1996). Instructional design of interactive multimedia: A cultural critique. Educational Technology Research and Development, 44(4), 85-104. doi: $10.1007 / \mathrm{bf02299823}$

Henderson, L. (2007). Theorizing a multiple cultures instructional design model for e-learning and e-teaching. In A. Edmondson (Ed.), Globalized e-learning cultural challenges (pp.130-153). Hershey, PA: IGI Global. doi:10.4018/9781599043012.ch008

Hollands, F., \& Tirthali, D. (2014). MOOCs - expectations and reality. Retrieved from http://www.academicpartnerships.com/sites/default/files/MOOCs_Expectations_and_Rea lity.pdf

Hollins, E. R. (1996). Culture in school learning: Revealing the deep meaning. Mahwah, NJ: Erlbaum.

Jacoby, J. (2014). The disruptive potential of the Massive Open Online Course: A literature review. Journal of Open, Flexible, and Distance Learning, 18(1), 73-85. Retrieved from http://www.jofdl.nz/index.php/JOFDL/article/view/214

Johari, A. (2005). Intercultural Internet-based learning: Know your audience and what it values. Educational Technology Research and Development, 53(2), 117-127. doi: $10.1007 / \mathrm{bf02504870}$

Ke, F., Chávez, A. F., \& Herrera, F. (2013). Web-based teaching and learning across culture and age. New York: Springer.

Kleinfeld, J. (1975). Effective teachers of Eskimo and Indian students. School Review, 83(2), 301-344. doi:10.1086/443191

Ladson-Billings, G. (1994). The dream-keepers: Successful teachers of African American children. San Francisco, CA: Jossey-Bass.

Ladson-Billings, G. (1995). Toward a theory of culturally relevant pedagogy. American Educational Research Journal, 32(3), 465-491. http://dx.doi.org/10.3102/00028312032003465

Liyanagunawardena, T., Adams, A., \& Williams, S. (2013). MOOCs: A systematic study of the published literature 2008-2012. The International Review of Research in Open and Distributed Learning, 14(3), 202-227. Retrieved from http://www.irrodl.org/index.php/irrodl/article/view/1455/2531

Llambi, L., Margolis, A., Toews, J., Dapueto, J., Esteves, E., Martinez, E., \& Lockyer, J. (2008). Distance education for physicians: Adaptation of a Canadian experience to Uruguay. Journal of Continuing Education in the Health Professions, 28(2), 79-85. doi: $10.1002 /$ chp.161

Martin, F. G. (2012). Will massive open online courses change how we teach? Communications of the ACM, 55(8), 26-28. Retrieved from http://dx.doi.org/10.1145/2240236.2240246

Merriam, S. B. (2009). Qualitative research: A guide to design and implementation. San Francisco, CA: Jossey-Bass.

Nieto, S. (1999). The light in their eyes: Creating multicultural learning communities. New York: Teachers College Press. 
Phan, T., McNeil S., \& Robin, B. (2016). Students' patterns of engagement and course performance in a massive open online course. Computers \& Education, 95, 36-44. Retrieved from http://dx.doi.org/10.1016/j.compedu.2015.11.015

Rivard, R. (2013). Learning how to teach. Inside Higher Ed. Retrieved from https://www.insidehighered.com/news/2013/03/05/moocs-prompt-some-facultymembers-refresh-teaching-styles

Smith, D., \& Ayers, D. (2006). Culturally responsive pedagogy and online learning: Implications for the globalized community college. Community College Journal of Research and Practice, 30(5-6), 401-415. doi:10.1080/10668920500442125

Stake, R. E. (2006). Multiple case study analysis. New York, NY: Guilford Press.

Stewart, B. (2013). Massiveness + openness = new literacies of participation? MERLOT Journal of Online Learning and Teaching, 9(2), 228-238. Retrieved from http://jolt.merlot.org/vo19no2/stewart_bonnie_0613.htm

Tomkin, J. H., \& Charlevoix, D. (2014). Do professors matter? Using an A/B test to evaluate the impact of instructor involvement on MOOC student outcomes. In Proceedings of the First ACM Conference on Learning@scale Conference (pp.71-78). Atlanta, GA: Learning@ scale.

Yin, R. K. (2014). Case study research: Design and methods (5th ed.). Los Angeles, CA: Sage.

Zhang, Y. (2013). Benefiting from MOOC. In J. Herrington, A. Couros, \& V. Irvine (Eds.), Proceedings of EdMedia: World Conference on Educational Media and Technology 2013 (pp. 1372-1377). Association for the Advancement of Computing in Education (AACE): Victoria, British Columbia. 